\title{
Synthesis of methyl-3-orsellinate by organic synthesis or by altered biosynthetic pathways using lichen immobilisates
}

\author{
Lauxo Xavier Filho, ${ }^{1}$ Eugenia C. Pereira, ${ }^{2}$ Carlos Vicente, ${ }^{3}$ and María-Estrella Legaz $^{3}$ \\ ${ }^{1}$ Universidade Tiradentes, Tomas D’Avila Nabuco 300. Farôlandia, Sergipe, Brazil. \\ ${ }^{2}$ Departamento de Ciencias Geograficas, Universidade Federal do Pernambuco, 5000 Recife, \\ Brazil. \\ ${ }^{3}$ Departamento de Fisiología Vegetal, Facultad de Biología, Universidad Complutense, 28040 \\ Madrid, Spain \\ E-mail:xavierfilho@unitnet.com.br
}

Dedicated to Prof. Otto Richard Gottlieb

(received 21 Feb 04; accepted 31 Mar 03; published on the web 8 Apr 04)

\begin{abstract}
Methyl-3-orsellinate can be generated from methyl-3-orcinol through the nitration of aryl function to be then reduced to amine group. This last derivative could be the substrat of a diazotonization for the corresponding diazonium salt. After this, a cyanide group could be introduced by nucleophilic substitution using potassium cyanide and then, the carboxyl function could be produced after hydrolysis. Alternatively, methyl-3-orsellinate could be produced by alginate-immobilized, atranorin-producing lichen cells loaded with acetate and treated with sodium azide. Acetate is used by acetyl-CoA carboxylase and aromatic synthase (methyl transfer) to produce methyl-3-orsellinate and its oxidation to haematommoyl alcohol is inhibited by sodium azide.
\end{abstract}

Keywords: Acetyl-CoA carboxylase, aromatic synthase, diazotonization, immobilized cells, methyl-3-orsellinate

\section{Contents}

1. Introduction

2. Production of methyl-3-orsellinate by organic synthesis

3. Bioproduction of methyl-3-orsellinate by immobilized lichen cells 


\section{Introduction}

Lichens produce depsides, phenolics composed by two or three monocyclic units linked by an ester bond and derived from orsellinic acid. Orsellinic acid is synthesized by an aromatic synthase ${ }^{1}$, which produces an $8 \mathrm{C}$ lineal polyketide intermediate before cyclasation. However, labelling experiments have indicated that an additional $\mathrm{C}-1$ unit must be added to the polyketide chain prior to cyclasation to produce $\beta$-methyl orsellinate, the basic unit of depsides of the $\beta$-orcinol series ${ }^{2,3}$. This additional $\mathrm{C} 1$ unit can be derivatized or oxidized to alcohol or aldehyde functions, such as occurs in atranorin. Depsides from the orcinol and $\beta$-orcinol series, such as lecanoric or evernic acids, and atranorin, respectively, are produced by esterification of two orsellinic acid, or orsellinate derivatives, catalyzed by several orsellinate depside hydrolases ${ }^{4,5}$ thus acting as esterases.

Many depsides are used for industrial or pharmacological purposes. For instance, atranorin and its derivatives are common constituents of the "oak moss absolute", characteristic of many parfums $^{6,7}$. Huneck ${ }^{8}$ reported that in 1997, 1900 tons of Pseudevernia furfuracea and 700 tons of Evernia prunastri, the most important species used for the production of essential ingredients of the oakmoss absolute, were processed, mainly at Grasse, the centre of the essential oil industry in France. Since atranorin is an inhibitor of elastase ${ }^{9}$, its use would arise great interest among the cosmetic industry. Moreover, usnic acid, another lichen phenol, is used as preservative in cosmetic creams ${ }^{10}$, and atranorin and other related compounds are potential sunscreen materials ${ }^{11}$. In spite of the applied interest for these substances, atranorin and other related compounds are regarded as responsible sensitizers in allergic contact and photocontact dermatitis to oakmoss ${ }^{12,13}$. To improve the skin tolerance to these compounds, Ehret et al., ${ }^{14}$ describe a treatment of oakmoss absolute with amino acids such as lysine and leucine which lowers the content of allergenic constituents. On the other hand, provided the slow rate of growth of lichens, the destruction of lichen biomass required to supply high amounts of these metabolites to the industry can be considered as irreversible.

Since atranorin seems to be a key compound for pharmaceutical and cosmetic industries, a simple procedure to obtain methyl-3-orsellinate as a precursor of haematommic acid is required in order to an efficient production of the depside.

\section{Production of methyl-3-orsellinate by organic synthesis}

The orcinol molecule is highly functionalized. To modify its structure in order to obtain methyl3-orsellinate, some reactions of electrophillic substitution can be attempted on the benzene ring to introduce the selected functions in the appropriate positions. Methylation at the position 2, between two hydroxyl functions, would produce methyl-3-orcinol with very low recovery, about 6-10\% (Scheme 1). 


\section{Scheme 1}

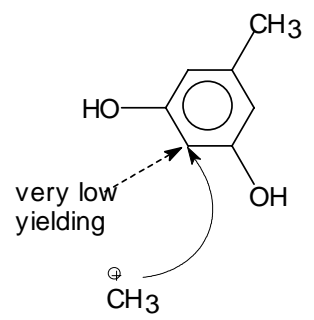

Moreover, all the positions in the orcinol molecule is activated for monosubstitution (Scheme 2). Thus, at least two different products could be obtained. This kind of methylation is achieved through a Friedel-Crafts reaction using methyl iodide and anhydre aluminium chloride as a catalizer in the appropriate solvent ${ }^{15}$. On the other hand, introduction of a carboxyl group can be achieved by oxidation of an alkyl group (generally, a methyl substituent).This implies a new methylation and then, a tri-methyl derivatives will be obtained (Scheme 3). In this case, it is impossible to carry out a selective oxidation with high recovery, since other products different than 1-caboxy-3-methyl orcinol can be obtained (Scheme 4).
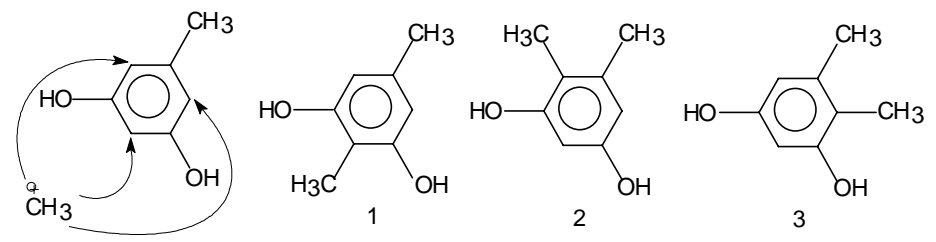

$$
2=3
$$

\section{Scheme 2}

\section{Scheme 3}
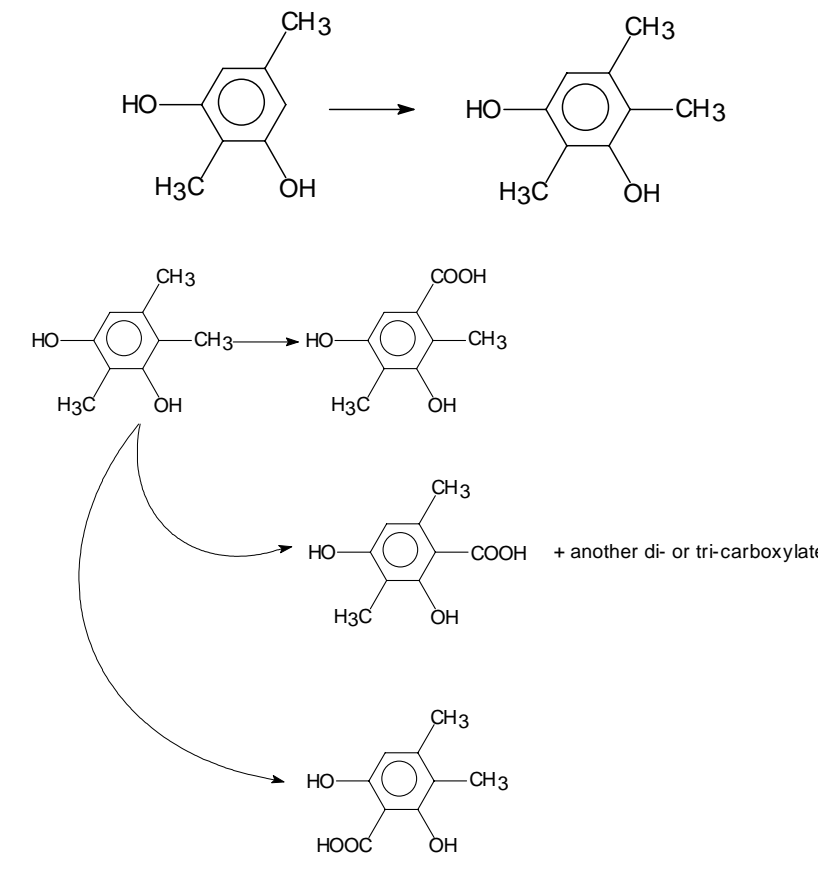

\section{Scheme 4}


An alternative possibility to generate a carboxyl group consists of a nitration of alkyl function to be then reduced to amine group. This last derivative could be the substrat of a diazotonization ${ }^{16,17}$ to for the corresponding diazonium salt. Reaction is carried out at $10^{\circ} \mathrm{C}$ and $\mathrm{pH}$ 3.5. After this, a cyanide group could be introduced by nucleophilic substitution using potassium cyanide ${ }^{18}$ and then, the carboxyl function could be produced after hydrolysis (Scheme 5). From the cyano-derivative, the product can be obtained according to the sequence of reactions shown in Scheme 6. Ammonia is derived from the cyano function by acidic hydrolysis and, after this, the carboxy derivative is methylated as above.
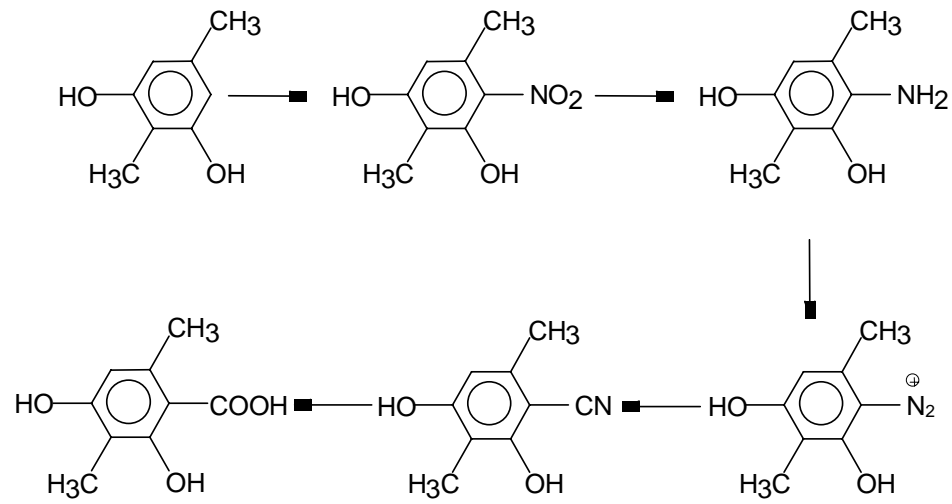

\section{Scheme 5}

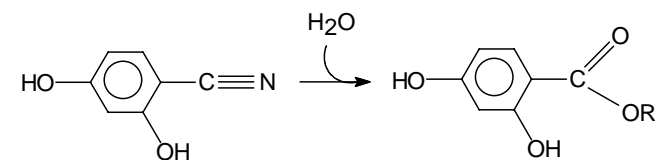

\section{Scheme 6}

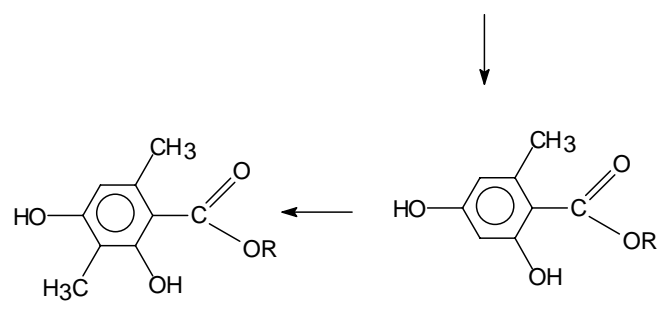

\section{Bioproduction of methyl-3-orsellinate by immobilized lichen cells}

Cells of the lichen Evernia prunastri, immobilized in calcium alginate, were able to produce the depside atranorin from acetate. The synthesis of the depside was enhanced by molecular oxygen and NADH. This enhancement suggested the participation of an oxydase (Scheme 7) and an alcohol dehydrogenase (Scheme 8) to produce an aldehyde-substituted phenolic acid, haematommic acid, as the most probable precursor of atranorin. The participation of both enzymes was confirmed by loading immobilized cells with sodium azide, an inhibitor of several 
metallo-oxydases, and pyrazole, an inhibitor of alcohol dehydrogenase, which impeded atranorin production $^{19}$ and accumulated $\beta$-methyl orsellinate (after azide loading) or its alcohol derivative (after pirazole treatment).

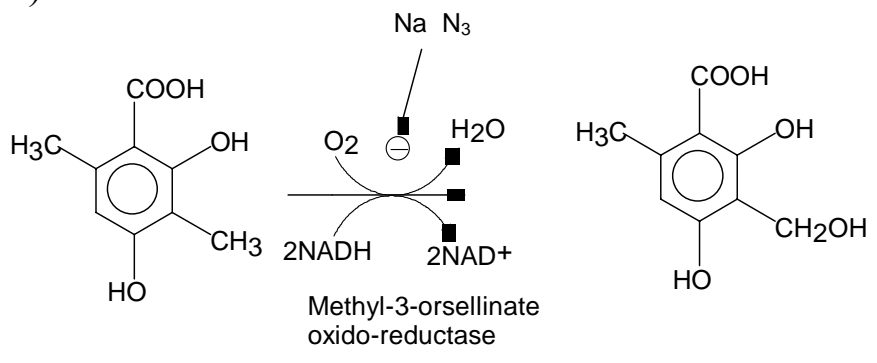

\section{Scheme 7}

\section{Scheme 8}

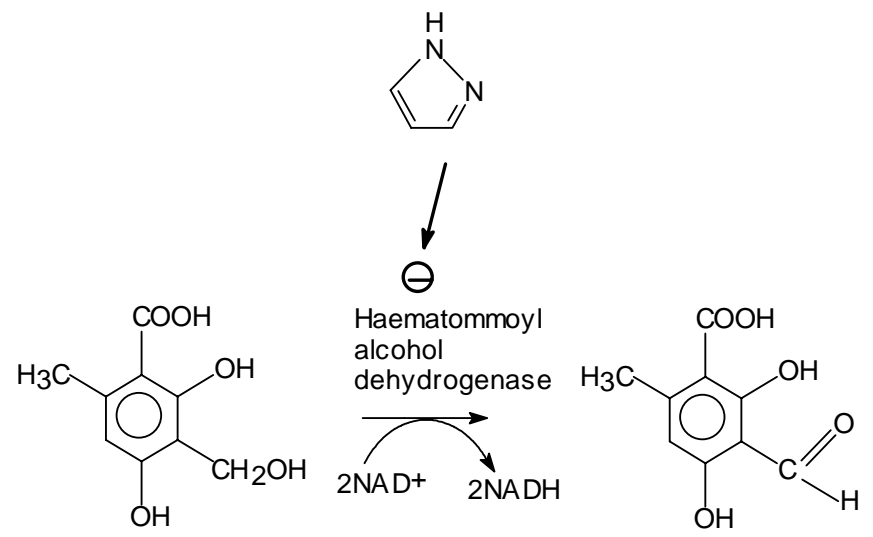

Samples of $2.0 \mathrm{~g}$ of dry thalli of the lichen Evernia prunastri were completely rinsed in distilled water and gently macerated in a mortar to obtain an homogenate. Then, $20 \mathrm{ml}$ of sodium alginate, medium viscosity, solution $(4 \%, \mathrm{w} / \mathrm{v})$ were added and mixed with the homogenate, and the mixture was extruded dropwise with a syringe into $50 \mathrm{ml}$ of $0.2 \mathrm{M} \mathrm{CaCl}_{2}{ }^{20}$. The beads of calcium alginate were supplemented with $50 \mathrm{ml} 1.0 \mathrm{mM}$ sodium acetate containing $14 \mathrm{M}$ $\mathrm{NADH}$, and $2 \%(\mathrm{v} / \mathrm{v})$ 2-propanol in order to permeabilize lichen cells ${ }^{21}$ and maintained, gently stirred, at $25^{\circ} \mathrm{C}$ for 10 days. Oxygen dissolved in the bath solution was increased by a continuous bubbling of air. When indicated, $20 \mu \mathrm{M}$ sodium azide or $10 \mu \mathrm{M}$ pyrazole were added to the acetate solution. After 10 days, the bath solution was collected to extract lichen phenolics.

Phenolics were extracted by mixing the bath solution with $50 \mathrm{ml}$ of diethyl ether:ethyl acetate $(65: 35 \mathrm{v} / \mathrm{v})$. The mixture was vigorously stirred and the organic phase was separated with a micropippette $^{22}$. The extraction was repeated three times. Organic extracts were mixed and dried in air flow. The residue was redisolved in $2.0 \mathrm{ml}$ methanol and analyzed by HPLC, according to Feige et al. ${ }^{23}$, using a Varian 5060 liquid chromatograph equipped with a Vista CDS 415 computer. A reverse phase MCH-10, $5 \mu \mathrm{m}, 250 \mathrm{~mm} \times 4.6 \mathrm{~mm}$ column was used. Two solvent systems were employed. System A was MilliQ water containing 1\% (v/v) orthophosphoric acid and system B was $100 \%$ methanol. The run started with $30 \% \mathrm{~B}$ and continued isocratically for 1 $\min$ at $0.7 \mathrm{ml} \mathrm{min}-1$. After $1 \mathrm{~min}, 10 \mu \mathrm{l}$ of the sample were injected and the solvent $\mathrm{B}$ was increased to $70 \%$ within $14 \mathrm{~min}$, then up to $100 \%$ in $30 \mathrm{~min}$, and then isocratically in $100 \% \mathrm{~B}$ for further $8 \mathrm{~min}$. At the end of the run the system B was decreased to $30 \%$ within 1 min and the 
column flushed with 30\% B for 16 min before a new run was started. Detection was carried out by using an UV set at $238 \mathrm{~nm}$. Atranorin and evernic acid from Sarsyntex (France), and usnic acid from Sigma Chemical Co. (USA) were used as external standards.

Chromatographic trace of phenolics extracted from media containing immobilized cells supplemented only with acetate or with acetate and NADH in the presence of additional amounts of oxygen revealed the production of atranorin (retention time value $41.60 \mathrm{~min}$ ) and evernic acid (retention time value $33.43 \mathrm{~min}$ ), as well as the appearance of peaks corresponding to usnic acid (retention time $49.15 \mathrm{~min}$ ) and chloroatranorin (retention time $43.55 \mathrm{~min}$ ) and other minor peaks, presumably corresponding to undetermined precursors or catabolites. However, when sodium azide, a well-known inhibitor of several oxydases ${ }^{24,25}$, was included in the oxygenated incubation medium containing NADH, the peak of usnic acid was newly detected and, in addition, a new peak appeared with a retention time value of $17.24 \mathrm{~min}$ after 10 days. However, those corresponding to major phenolics completely disappeared. The relative retention time of this new substance with respect to that of evernic acid and atranorin was almost identical to that found by Feige et al. $^{23}$ for methyl-3-orsellinate, presumably accumulated in the bath medium as a consequence of the inhibition of a specific oxydase by sodium azide (Scheme 9).

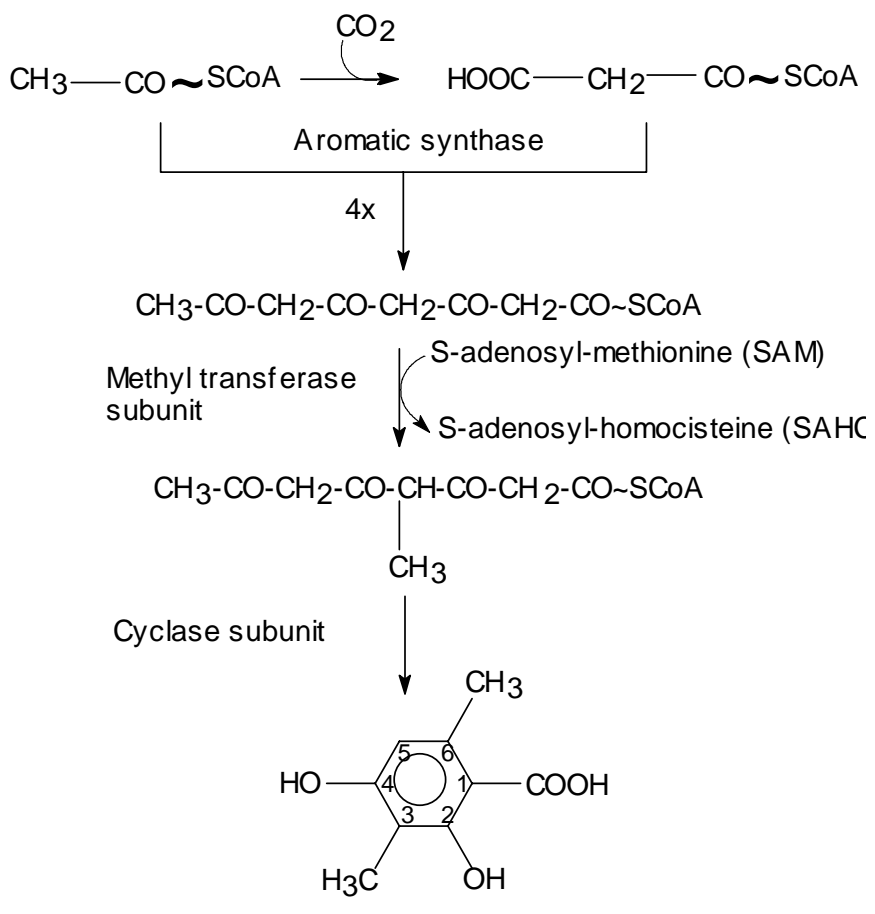

Methyl-3-orsellinate (w hich accumulates

\section{Scheme 9}

in the presence of sodium azide) 


\section{Acknowledgements}

This work was supported by a grant from the Dirección General de Investigación Científica y Técnica (Ministerio de Ciencia y Tecnología, Spain), No. BFI 2000-0610. We wish to thanks Miss Raquel Alonso for her excellent technical assistance.

\section{References}

1. Gaucher, G.M.; Shepherd, M.G. Biochem. Biophys. Res. Commun. 1968, 32, 664.

2. Yamazaki, M.; Matsuo, M.; Shibata, S. Chem. Pharm. Bull. 1965, 13, 1015.

3. Yamazaki, M.; Shibata, S. Chem. Pharm. Bull. 1966, 14, 96.

4. Schultz, J.; Mosbach, K. Eur. J. Biochem. 1971, 22, 153.

5. Vicente, C. Symbiosis 1991, 11, 279.

6. Richardson, In Handbook of Lichenology Galun, M., Ed., CRC Press: Boca Raton, 1988.

7. Schultz, H.; Albroscheit, G. J. Chromatogr. 1989, 466, 301.

8. Huneck, S.. Progr. Chem. Org. Nat. Prod. 2001, 81, 1.

9. Proksa, B.; Adamcova, J.; Sturdikova, M.; Fuska, J. Pharmazie 1994, 49, 282.

10. Seifert, P.; Bertram, C. Seifen Öle Fette Wachse 1995, 121, 480.

11. Fernández, E.; Quilhot, W.; González, I.; Hidalgo, M.E.; Molina, X.; Meneses, I. Cosm. \& Toilet 1996, 111: 69.

12. Thune, P.O.; Solberg, Y.J.; McFadden, N.; Staerfelt, F.; Sandberg, M. Contact Dermat. 1982, 8, 396.

13. Hausen, B.M.; Emde, L.; Marks, V. Contact Dermat. 1993, 28, 70.

14. Ehret, C.; Maupetit, P.; Petrzilka, M.; Klecak, G. Intern. J. Cosm. Sci. 1992, 14, 121.

15. Ma, S.M.; Zhang, J.L. Tetrahedron 2003, 59, 6273.

16. Barraja, P.; Diana, P.; Lauria, A.; Almerico, A.M.; Dattolo, G.; Cirrincione, G. Helv. Chim. Acta 2001, 84, 2212.

17. Seymour, E.H.; Lawrence, N.S.; Pandurangappa, M.; Compton, R.G. Microchim. Acta 2002, 140, 211.

18. Roshchupkina, G.I.; Rybalova, T.V.; Gatilov, Y.V.; Reznikov, V.A. Eur. J. Org. Chem. 2003, 18, 3599.

19. Vicente, C., Fontaniella, B., Millanes, A.M.; Sebastián, B.; Legaz, M.E. Intern. J. Cosm. Sci. 2003, 25, 25.

20. Kierstan, M.P.J.; Coughlan, M.P. In Immobilized Cells and Enzymes. A Practical Approach, Woodward, J. Ed.; IRL Press: Oxford, 1985.

21. Fontaniella, B.; Legaz, M.E.; Pereira, E.C.; Sebastian, B.; Vicente, C. Biotechnol. Lett. 2000, 22, 813.

22. Pedrosa, M.M.; Legaz, M.E. Plant Physiol. (Life Sci. Adv.) 1991, 10, 57.

23. Feige, G.B.; Lumbsch, H.T.; Huneck, S.; Elix, J.A. J. Chromatogr. 1993, 646, 417.

24. Varotsis, C.; Vamvouka, M. J. Phys. Chem. B 1999, 103, 3942.

25. Zajoncova, L.; Frebort, I.; Luhova, L.; Sebela, M.; Galuszka, P.; Pec, P. Biochem. Mol. Biol. Intern. 1999, 47, 47. 